\title{
PRACTICE
}

\section{Learning "Scholarship as Conversation" by Writing Book Reviews}

Nicholas Rowland, Penn State Altoona

Jeffrey A. Knapp, Hailley Fargo, Penn State University Park

\begin{abstract}
The ability of undergraduate students to write for scholarly audiences is contingent upon their capacity to recognize that scholarship is a kind of conversation. For a student, writing an academic book review is a near ideal yet generally underutilized opportunity to learn this lesson. Through analysis of previously published book reviews coproduced with students, the authors identify actionable practices to transform the process of writing book reviews from an undervalued, lone activity into a viable form of undergraduate research. Publishing coauthored book reviews may aid students seeking admission to graduate school and faculty seeking promotion. In the end, writing book reviews with students is an opportunity for faculty and librarians to pass along the important lesson that scholarship is an important, inclusive conversation.
\end{abstract}

Keywords: book reviews, information literacy, librarians, undergraduate research

doi: 10.18833/spur/2/3/6

The idea that scholarship is a kind of conversation guides and gives purpose to this article. One way to bring undergraduate students into discipline-relevant conversations is for mentors to write academic book reviews with them. Scholars in library science have developed a conceptual framework around information literacy that regards "scholarship as conversation," which the authors adopt to frame their contribution. After reflecting on the current status of academic book reviews, the scholarship as conversation lens is used to analyze book reviews coproduced with students over the past decade. In doing so, actionable practices are identified that transform the process of writing book reviews from an undervalued, lone activity into a viable form of undergraduate research that is engaging and productive for students and their mentors. Understood in this light, publishing coauthored book reviews can help faculty members earn promotion (and/or tenure) and aid undergraduates applying to graduate school. To this end, the authors review literature developed by the Association of College \& Research Libraries on information literacy, discuss academic book reviews, demonstrate the scholarship as conversation framework in an analysis of book reviews, and then provide concluding remarks.

\section{Framing Scholarship as Conversation}

The Association of College \& Research Libraries (ACRL) adopted Framework for Information Literacy for Higher Education, an overhaul of the 2000 Information Literacy Competency Standards for Higher Education, in 2016. Information literacy is defined as a "set of integrated abilities encompassing the reflective discovery of information," which includes an "understanding of how information is produced" and "ethically [created] in communities of learning" (ACRL 2016, 2). More flexible than standards, frames for information literacy are based on "interconnected core concepts" that address undergraduate research in addition to other curricular and cocurricular experiences (12). The six frames include recognition that "authority is constructed and contextual" and that "information has value"; additionally, the frames portray "information creation as a process," "research as inquiry," "scholarship as conversation," and "searching as strategic exploration" (2). 
The "scholarship as conversation" frame is germane to the current discussion. It implies recognition that "communities of scholars, researchers, or professionals engage in sustained discourse with new insights and discoveries occurring over time as a result of varied perspectives and interpretations" (ACRL 2016, 8). The frame includes "knowledge practices," which are skills that students are expected to exhibit as they expand their knowledge base, and scholarly "dispositions," which are attitudes and perspectives that students gradually adopt as they participate in knowledge practices. This article demonstrates knowledge practices rather than shifts in disposition because the main data source (i.e., book reviews) can provide evidence for the former and not the latter. Knowledge practices for the conversation frame include the ability to:

- cite the contributing work of others in their own information production;

- contribute to scholarly conversation at an appropriate level, such as local online community, guided discussion, undergraduate research journal, conference presentation/ poster session;

- identify barriers to entering scholarly conversation via various venues;

- critically evaluate contributions made by others in participatory information environments;

- identify the contribution that particular articles, books, and other scholarly pieces make to disciplinary knowledge;

- summarize the changes in scholarly perspective over time on a particular topic within a specific discipline;

- recognize that a given scholarly work may not represent the only-or even the majority-perspective on the issue. (ACRL 2016, 8)

As this article demonstrates, knowledge practices can be transformed into a rubric for assessing student work.

In the context of undergraduate research, Willison and Buisman-Pijlman $(2016,68)$ state that the highest achievement of the undergraduate researcher is to contribute to the "conversation in the discipline" (see also Willison and O'Regan 2007). Hensley, Shreeves, and Davis-Kahl (2014, 423) concur, stating that students need "skills addressing the undergraduate student's role as author" (see also Stamatoplos 2009). Adopting facets of the information literacy framework answers these calls. Librarians are already positioned to meet faculty halfway. According to the literature, librarians already engage students by rewarding undergraduate research (Overby et al. 2014), through direct mentoring (Harwood and McCormack 2008; Piazza, Smith, and Pollenz 2016) and curricular and cocurricular development (Ivey 2003; Moselen and Wang 2014; Taib and Holden 2013), and by partnering with engaged faculty (Torres and Jansen 2016; Wijayasundara 2008). In some institutions, student engagement is such a priority that the physical structures of libraries are being built to facilitate collaboration among students, faculty, and librarians (Baril and Kobiela 2017). Still, it would be remiss not to admit that the direct impact of information literacy on undergraduate research is not well known and difficult to assess (Christiansen, Stombler, and Thaxton 2004; Hensley et al. 2014; Linn et al. 2015; McGuinness 2003, 2006; Weetman 2005).

\section{Writing Book Reviews}

It is precisely because book reviews have low perceived utility in contemporary academia that using them to teach scholarship as conversation is so potentially transformative. Essays like "The Endangered Scholarly Book Review" (Worsham 2012) and "Why Bother Writing Book Reviews?" (Toor 2012) act as harbingers, warning faculty to avoid reviewing books. "Buried under their own work," Toor (2012) asks, why would any faculty voluntarily "bother to write one?" Remuneration and recognition are nonexistent. In terms of priority, "is the time spent reviewing other peoples' books more important than writing your own stuff, making your own contributions?" Toor's answer is no. Even if it were not, according to Worsham (2012), journal editors are still reluctant to publish book reviews, as a cost-savings measure (because there are simply too many books to review), and for fear that readers do not read them.

Whatever residual value book reviews hold is framed in terms of "conversation." "We are invested in our fields," Toor (2012) acknowledges, and faculty "want to be involved in a conversation about where they should go." Even Worsham (2012) admits, "a review section contributes to the scholarly conversation." If the last hope of book reviews hinges on joining the scholarly conversation, then getting students involved in the effort makes sense. Still, students should not join the conversation alone. Learning "scholarship as conversation" by writing book reviews requires balancing expertise gained from discipline-relevant faculty with information literacy training from librarians.

\section{Joining the Conversation}

The following paragraphs analyze book reviews coproduced by faculty, students, and librarians using the practices associated with the ACRL's conversation frame as a rubric. Then some best practices for faculty writing with students and librarians are distilled. For context, Rowland began reviewing books with students in 2010 and has sought out librarian support to improve reviews ever since.

(1) Students must "cite the contributing work of others in their own information production" (ACRL 2016, 8). All reviewers cite the book they review, usually in the title or in an opening passage. But the reference here is to evidence from information production (i.e., published book reviews) of students' ability to include material 
outside of the book under review. This can be fruitfully framed for students as a question: "where does this book belong on the bookshelf?" The prompt challenges students to discover what other books the book under review is in conversation with. For example, in a review of Shifman's (2014) Memes in Digital Culture, the following passage on "fit" was developed collaboratively by faculty member, student, and librarian:

Attentive readers will recognize portions of the brief book from Shifman's (2012; 2013) body of already published work[.] ... Appropriate for undergraduates or as a primer for seasoned scholars who have not yet happened upon this burgeoning area in the digital humanities, this book sits alongside Wiggins and Bowers's (2015) work on memes as a "genre," detailed analysis of the "It Gets Better" meme by Gal, Shifman, and Kampf (2016), and research about "sharing" and "participation" on the Web by John (2013) (Lehman, Rowland, and Knapp 2016, 162).

By positioning the book on the proverbial library shelf, students are forced to cite the work of others and articulate the relationship between that work and the book under review in the process of "their own information production" (ACRL 2016, 8).

(2) Students must "contribute to scholarly conversation at an appropriate level" (ACRL 2016, 8). There is a perception that only experts should review books for an expert audience. In fact, after writing a review of multiple books with a student coauthor, Rowland was prohibited from listing the student as a coauthor. The editor, in email correspondence, indicated that student coauthors "detract from the very legitimacy good reviews need" and, as "non-experts, no reader should be expected to believe that a student can contribute to the conversation among the books under review." In disciplinary areas where multiple authors, including students and librarians, are common, this barrier will matter less. Still, consider communicating the intention to coauthor reviews with the editor to address possible concerns that students are incapable of contributing to the scholarly conversation at "an appropriate level" in a given journal (ACRL 2016,8). The faculty member need only ask: "have I discussed student coauthors with the editor?"

(3) Students must "identify barriers to entering scholarly conversation" (ACRL 2016, 8). This has two parts for student coauthors. First, students are asked: "what barriers do you face, as a student or students, to entering scholarly conversation?" Students willingly identify multiple barriers within themselves (e.g., "are my writing skills adequate?"), their institutions (e.g., "have my writing, classes prepared me for this?"), and academia more broadly (e.g., "will I be taken seriously as an author if readers know I am a student?"). Acknowledging how to address barriers, how adopting practices associated with information literacy helps overcome them, and how close mentoring will shepherd the student through the process is difficult but often has the effect of motivating students to perform at their best. Second, this practice also asks students to identify, in a review, "what barriers do authors face in joining the scholarly conversation?" This is a challenge for students, because barriers to authors are often not obvious to newcomers. Errors, however, are a good example. In a review of O'Donnell's (2014) first book, Developer's Dilemma, the review authors identify barriers to being taken seriously among experts based on repetition and errors in the book:

... the author exposes the reader to abundant repetitiveness. While this is not immediately obvious, eventually the reader sees "[a]s mentioned before" (118), "[a]s previously mentioned" (126), "as already noted" (130), "[a]s previously noted" (193), and so on. ... Also, occasional errors will madden close readers. For example, amid rich data, we see "their labor associated with a games [sic] development disappears" (105), or, when the apostrophe is used, it may appear backward: "I'm [sic] hoping we'll [sic] do more of those kinds of things" (85) (Rowland and Lucia 2016, 366).

Once students learn that even the most minor error calls into question an author's attention to detail, they become closer readers. This practice also serves to make students more careful writers, and they are often quick to acknowledge that it is hypocritical to point out errors in the work of others if equal attention is not paid to one's own published work. This also translates to subsequent classroom writing.

(4) Students must "critically evaluate contributions made by others" (ACRL 2016, 8). Academic book reviews critically evaluate the book under review by design; however students are asked not only to examine the author's grammar and ideas but also to evaluate the book's overall structure. In a review of Rogers's (2016) How Video Games Impact Players, the review authors critically evaluate the book's structure:

After reading the brief introduction and the author's heartfelt desire to provide a single, balanced assessment to readers, one expects to find a book that flows from one topic to the next as it discusses key concepts as they relate to each chapter's topic. However, there is a structural barrier to achieving flow. Each chapter ends with a reference section as if it were a stand-alone article. The citations, many of which are shamelessly repeated in other chapters, bring a hard stop to the chapters, rather than contributing to their balanced integration. (Lehman and Rowland 2017, 172)

Developing a sensitive eye for a book's structure or citation standards is a key element of seeing scholarship as conversation; the aim is to distance students from evaluating 
a book based on their subjective interest in a topic, and, instead, to evaluate a book based on what the book aims to accomplish and in accordance with standards in the book's field of study. Students are prompted by asking: "without focusing on what you subjectively liked or disliked about the book, what is good or bad, effective or ineffective in the author's efforts to join the conversation?"

(5) Students must "identify the contribution ... scholarly pieces make to disciplinary knowledge” (ACRL 2016, 8). Students are asked: "what is the distinctive contribution this book makes to knowledge that no or few other books make?" Again, this distances students from "what they found interesting" and sensitizes them to what is unique about a text. In a review of Altice's (2015) I AM ERROR, reviewers characterize a bibliographic referencing innovation for the citation of video games as a major contribution to literature in the digital humanities:

In closing, the book is a model for research in the digital humanities. Acknowledging demand for more detailed descriptions in the fan community, Altice demonstrates a thorough and thoughtful method for producing bibliographic references for videogames (see his Appendix A). Similarly, professional cataloging librarians provide bibliographic references for media to scholars, another kind of fan community. As the digital humanities grow and research on videogames continues to lead the way, cataloging librarians could gain some valuable insight regarding how to cite videogames using Altice's technique. After reading this book, we now all fully agree that the simple claim "I cite Donkey Kong in my bibliography" is not an innocent statement. To the cataloging librarian, further distinction is badly needed. (Rowland et al. 2016, 77)

Students report feeling like they are searching for the proverbial needle in a haystack occasionally, but often book authors go out of their way to ensure that readers understand their primary contribution. The learning gains, in this case, come to students when they realize what a contribution means and that authors often carefully signpost the significance of contributions.

(6) Students must "summarize the changes in scholarly perspective over time” (ACRL 2016, 8). One way for students to accomplish this knowledge practice is to position the book under review in the context of an author's other work. In a review of Ehrenreich's (2009) Bright-Sided, the review authors place her new book in the context of her other written work:

Readers looking for another empirical project like Nickel and Dimed (2002) will be woefully disappointed with Bright-Sided as Ehrenreich offers only one auto-ethnographic chapter documenting her experience with breast cancer. Someone hunting for a book about breast cancer may walk away wanting more. Likewise, this book is not a compendium of previously published essays (Ehrenreich 2008). (Rowland and Singer 2012, 72)

Large-scale changes in scholarly perspective are difficult to capture in the context of a single book review; however, by putting the book under review into conversation with other work by the same author (or another author), students come closer to demonstrating the intent of the practice. Students are prompted: "how does this book fit into previously published work by the same author or similar work from other authors?" Experience has shown that the answer to this question is most commonly found at the library with librarian support, which is the very origin of this project.

(7) Students must recognize that "scholarly work may not represent the only ... perspective on the issue" (ACRL 2016, 8). An innovative way to ensure students exercise this knowledge practice is to have them identify other reviews of the same book, indicating that, as review authors, they do not consider their review to be the "only ... perspective on the issue" $(2016,8)$. In a review of Skocpol and Williamson's (2012) The Tea Party and the Remaking of Republican Conservatism, the reviewers point out a strength of the book but, crucially, not without acknowledging that other reviewers have shared the same assessment - in this case, before the student reviewers did. They write:

a key strength of Skocpol and Williamson's, as noted by other reviewers (Bush 2011; Ventura 2012), was their ability to clearly differentiate between the national Tea Party groups and the grassroots activism, which some adherents believe is the "true" movement. (Branch, Pyeatt, and Rowland 2012, 75)

Additionally, in the review of Developer's Dilemma (O'Donnell 2014), consider this comment referencing another review of the same book that explicitly acknowledges that the review authors do not have the only perspective on the book:

the lasting academic impact of this book will no doubt be its foundational empirical contribution with regard to the real lives of game developers and the practices O'Donnell documents associated with production of video games in our postmodern times. Additionally, for reasons that Taylor (2015) outlines, it also seems that O'Donnell, who has dwelled on both sides of the gate, wants some attention from the world of gaming, too, and has hopes of qualitatively improving that world. (Rowland and Lucia 2016, 367)

Admittedly, finding other reviews of the same book, in search of differences or overlap in interpretation, is not always possible. If a faculty member and their students are 
the first to review a book, then there are logically no other reviews to reference. However, when they are available, they enrich the review and provide the student with an opportunity to display information literacy skills.

\section{Conclusion}

The ability of undergraduate students to write for a scholarly audience is contingent upon their capacity to recognize that scholarship is a kind of conversation. Coauthoring an academic book review is a near ideal yet generally underutilized opportunity to learn this lesson. Table 1 is a basic rubric of best practices, based on analysis of previously published book reviews coproduced with students. By transforming knowledge practices associated with information literacy into conversation-ready questions that faculty, students, and librarians can ask while crafting a book review, attempts have been made to make the practices more accessible and useful. The rubric also may be useful to faculty members writing book reviews without coauthors.

Consideration is given to the utility of published, coauthored book reviews for students seeking admission to graduate school and also for faculty and librarians seeking promotion and/or tenure. For students seeking entrance to graduate school or employment, being a published author adds some gravity to their budding CVs and resumes. The opportunity, because the review is published, comes at a relatively low cost to faculty, given that reviews are rarely rejected and generate a high reward for students. The work of reviewing books with student coauthors is admittedly slow, but it is found that the chance to do nontrivial work motivates most students. Additionally, students learn an important lesson about putting their name on a piece of written work. Although, as a matter of course, all of them have put their names on their course papers, publishing with a faculty member means that the faculty member or librarian can demand students write the best work they have ever done.

For faculty and librarians seeking promotion or tenure, book reviews are not a quick path to upward mobility in contemporary academia. However, by turning book reviews into an engaged scholarship or undergraduate research opportunity for students in the context of hired work, an independent study, or as part of an ongoing research laboratory experience, the endeavor produces an artifact that is evidence of teaching, research, and service. Students must be trained to contribute to a book review; hence, the teaching contribution. The review itself contributes to the scholarly conversation in the discipline: the research contribution. Service comprises mentoring students through high-impact practices like manuscript preparation and familiarization with the world of publishing and contributing to missioncritical activities like inspiring, motivating, and cultivating students. In the end, the noble, humble book review, coauthored with students, is an opportunity for faculty and librarians to pass along the important lesson that scholarship is an important, inclusive conversation.

\section{References}

Altice, Nathan. 2015. I AM ERROR: The Nintendo Family Computer/Entertainment System Platform. Cambridge, MA: MIT Press. doi: 10.1080/01972243.2016.1107362

Association of College \& Research Libraries. 2000. Information Literacy Competency Standards for Higher Education (report). Accessed March 1, 2018. alair.ala.org/handle/11213/7668

Association of College \& Research Libraries. 2016. Framework for Information Literacy for Higher Education (report). Accessed March 1, 2018. www.ala.org/acrl/standards/ilframework

Baril, Kathleen, and Kelly Kobiela. 2017. "Reimagining the Library: Designing Spaces to Meet the Needs of Today's Students." Scholarship and Practice of Undergraduate Research 1(2): 18-23. doi: 10.18833/spur/1/2/9

Branch, Joshua, Nicholas Pyeatt, and Nicholas J. Rowland. 2012. Review of The Tea Party and the Remaking of Republican Conservatism, by Theda Skocpol and Vanessa Williamson. Sociological Viewpoints 28: 74-78.

Bush, Vanessa. 2011. "The Change I Believe In: Fighting for Progress in the Age of Obama." Booklist 108(5): 10.

Christiansen, Lars, Mindy Stombler, and Lyn Thaxton. 2004. "A Report on Librarian-Faculty Relations from a Sociological Perspective." Journal of Academic Librarianship 30: 116-121. doi:10.1016/j.acalib.2004.01.003

Ehrenreich, Barbara. 2002. Nickel and Dimed: On (Not) Getting By in America. New York: Holt.

Ehrenreich, Barbara. 2008. This Land Is Their Land: Reports from a Divided Nation. New York: Metropolitan Books.

Ehrenreich, Barbara. 2009. Bright-Sided: How the Relentless Promotion of Positive Thinking Has Undermined America. New York: Metropolitan Books.

Gal, Noam, Limor Shifman, and Zohar Kampf. 2016. "“It Gets Better': Internet Memes and the Construction of Collective Identity." New Media \& Society 18: 1698-1714. doi: $10.1177 / 1461444814568784$

Harwood, Doreen, and Charlene McCormack. 2008. "Growing Our Own: Mentoring Undergraduate Students." Journal of Business \& Finance Librarianship 13: 201-215. doi: $10.1080 / 08963560802183195$

Hensley, Merinda K., Sarah L. Shreeves, and Stephanie DavisKahl. 2014. "A Survey of Library Support for Formal Undergraduate Research Programs." College \& Research Libraries 75: 422-441. doi: 10.5860/crl.75.4.422

Ivey, Ruth. 2003. "Information Literacy: How Do Librarians and Academics Work in Partnership to Deliver Effective Learning Programs?" Australian Academic \& Research Libraries 34: 100. doi: $10.1080 / 00048623.2003 .10755225$

John, Nicholas A. 2013. "Sharing and Web 2.0: The Emergence 
TABLE 1. Rubric for Assessing Book Review Manuscripts Based on Information Literacy Knowledge Practices

\begin{tabular}{|c|c|c|}
\hline Criteria & Discussion questions & Assessment questions \\
\hline \multicolumn{3}{|c|}{ (1) Work of others } \\
\hline & $\begin{array}{l}\text { - Where does this book belong on the bookshelf? } \\
\text { What other books would we expect to see next to this one } \\
\text { on a library shelf? }\end{array}$ & $\begin{array}{l}\text { Do the coauthors cite other books similar } \\
\text { to the book under review? }\end{array}$ \\
\hline \multicolumn{3}{|c|}{ (2) Appropriate level } \\
\hline & $\begin{array}{l}\text { - Has the faculty member discussed student coauthors with } \\
\text { the editor? } \\
\text { - Have the faculty member and student discussed the perception } \\
\text { that students are sometimes seen as nonexperts? }\end{array}$ & $\begin{array}{l}\text { - Has the editor assured the faculty member } \\
\text { that student coauthors are appropriate for } \\
\text { the journal before starting to write? }\end{array}$ \\
\hline \multicolumn{3}{|c|}{ (3a) Identify barriers, student perspective } \\
\hline & $\begin{array}{l}\text { - What barriers do you face, as a student or students, to entering } \\
\text { scholarly conversation? } \\
\text { - What limits students' ability to join scholarly conversations? }\end{array}$ & $\begin{array}{l}\text { Have the coauthors identified and } \\
\text { addressed barriers to students entering } \\
\text { the scholarly conversation before starting } \\
\text { to write? }\end{array}$ \\
\hline \multicolumn{3}{|c|}{ (3b) Identify barriers, author perspective } \\
\hline & $\begin{array}{l}\text { What barriers do authors face in joining the scholarly } \\
\text { conversation? } \\
\text { - What reasons might account for authors struggling to join the } \\
\text { scholarly conversation? }\end{array}$ & $\begin{array}{l}\text { Have the coauthors identified barriers to } \\
\text { joining the conversation in the book under } \\
\text { review? }\end{array}$ \\
\hline \multicolumn{3}{|c|}{ (4) Evaluate the contributions of others } \\
\hline & $\begin{array}{l}\text { Without focusing on what you liked or disliked about the } \\
\text { book, what is good or bad, effective or ineffective in the } \\
\text { author's efforts to join the conversation? } \\
\text { - What are standards of good or bad in the discipline of the } \\
\text { book under review? }\end{array}$ & $\begin{array}{l}\text { Have the coauthors critically evaluated } \\
\text { the contribution made by the author under } \\
\text { review? }\end{array}$ \\
\hline \multicolumn{3}{|c|}{ (5) Disciplinary contributions } \\
\hline & $\begin{array}{l}\text { What is the distinctive contribution this book makes to } \\
\text { knowledge that no or few other books make? } \\
\text { - What does this book accomplish that is unique in a given } \\
\text { disciplinary area? }\end{array}$ & $\begin{array}{l}\text { Have the coauthors identified the } \\
\text { distinctive contribution made by this book } \\
\text { in a given disciplinary area? }\end{array}$ \\
\hline \multicolumn{3}{|c|}{ (6) Changes to perspective over time } \\
\hline & $\begin{array}{l}\text { - How does this book fit into previously published work by } \\
\text { the same author or similar work from other authors? } \\
\text { - See also (1) "Work of others." }\end{array}$ & $\begin{array}{l}\text { Have the coauthors positioned the review } \\
\text { in the context of previously published } \\
\text { work by the same author or work of similar } \\
\text { authors? }\end{array}$ \\
\hline \multicolumn{3}{|c|}{ (7) Not the only perspective } \\
\hline & $\begin{array}{l}\text { - How do other reviews of the book characterize it? } \\
\text { What do coauthors agree with or disagree with in other } \\
\text { reviews of the same book? }\end{array}$ & $\begin{array}{l}\text { Have the coauthors positioned the review } \\
\text { in the context of other reviews, if } \\
\text { available? }\end{array}$ \\
\hline
\end{tabular}

Note: This table is meant to foster a conversation among faculty, student, and librarian coauthors and inform directions for revision. The rubric is presented in the same order as in the Association of College \& Research Libraries' (2016) Information Literacy Competency Standards for Higher Education; however, upon close inspection, (2) "appropriate level" and (3a) "identify barriers, student perspective" should be considered before all other rubric criteria.

of a Keyword." New Media \& Society 15: 167-182. doi: $10.1177 / 1461444812450684$

Lehman, Christopher D., and Nicholas J. Rowland. 2017. "How Video Games Impact Players: The Pitfalls and Benefits of a Gaming Society." Information Society 33: 172-173. doi: $10.1080 / 01972243.2017 .1296283$
Lehman, Christopher, Nicholas J. Rowland, and Jeffrey A. Knapp. 2016. Review of Memes in Digital Culture, ed. Limor Shifman. Information Society 32: 162-163. doi: 10.1080/01972243.2016.1130504

Linn, Marcia C., Erin Palmer, Anne Baranger, Elizabeth Gerard, and Elisa Stone. 2015. "Undergraduate Research Experiences: 
Impacts and Opportunities." Science 347: 627. doi: 10.1126/ science. 1261757

McGuinness, Claire. 2003. "Attitudes of Academics to the Library's Role in Information Literacy Education." In Information and IT Literacy: Enabling Learning in the 21st Century, ed. Allan Martin and Hannelore Rader, 244-254. London: Facet.

McGuinness, Claire. 2006. "What Faculty Think: Exploring the Barriers to Information Literacy Development in Undergraduate Education." Journal of Academic Librarianship 32: 573-582. doi: 10.1016/j.acalib.2006.06.002

Moselen, Chris, and Li Wang. 2014. "Integrating Information Literacy into Academic Curricula: A Professional Development Programme for Librarians at the University of Auckland." Journal of Academic Librarianship 40: 116-123. doi: 10.1016/j. acalib.2014.02.002

O'Donnell, Casey. 2014. Developer's Dilemma: The Secret World of Videogame Creators. Cambridge, MA: MIT Press.

Overby, Lynnette, Roger Strong Jr., Mark Christel, Gretchen Sneff, Gregory McKinney, and Rebecca Maniates. 2014. "Creating Value through Prizes for Undergraduate Research in Sustainability." CUR Quarterly 35(1): 18-20.

Piazza, Lisa M., Drew Smith, and Richard S. Pollenz. 2016. "Librarians Partner across Campus to Support Undergraduate Research." CURQ on the Web 36(4): 4-9. doi: 10.18833/curq/36/4/1

Rogers, Ryan. 2016. How Video Games Impact Players: The Pitfalls and Benefits of a Gaming Society. Lanham, MD: Lexington Books.

Rowland, Nicholas J., Frank Joseph, Jeffrey A. Knapp, and Chris Lehman. 2016. Review of I Am Error: The Nintendo Family Computer/Entertainment System Platform, by N. Altice. Information Society 32: 76-77. doi: 10.1080/01972243.2016.1107362

Rowland, Nicholas J., and Christian Lucia. 2016. Review of Developer's Dilemma: The Secret World of Videogame Creators, by Casey O'Donnell. Information Society 32: 366-367. doi: 10.1080/01972243.2016.1212622.

Rowland, Nicholas J., and Mark Singer. 2012. Review of BrightSided: How the Relentless Promotion of Positive Thinking Has Undermined America, by Barbara Ehrenreich. Sociological Viewpoints 28: 72-73.

Shifman, Limor. 2012. “An Anatomy of a YouTube Meme.” New Media \& Society 14: 187-203. doi: 10.1177/1461444811412160

Shifman, Limor. 2013. "Memes in a Digital World: Reconciling with a Conceptual Troublemaker." Journal of Computer-Mediated Communication 18: 362-377. doi: 10.1111/jcc4.12013

Shifman, Limor. 2014. Memes in Digital Culture. Cambridge, MA: MIT Press. doi: 10.1108/oir-06-2014-0145

Skocpol, Theda, and Vanessa Williamson. 2012. The Tea Party and the Remaking of Republican Conservatism. New York: Oxford University Press. doi: 10.1093/acprof:oso bl/9780199832637.001.0001

Stamatoplos, Anthony. 2009. "The Role of Academic Libraries in Mentored Undergraduate Research: A Model of Engagement

26 Scholarship and Practice of Undergraduate Research in the Academic Community." College \& Research Libraries 70: 235-249. doi: 10.5860/crl.70.3.235

Taib, Anne, and Julie Holden. 2013. “Third Generation' Conversations: A Partnership Approach to Embedding Research and Learning Skills Development in the First Year; A Practice Report." International Journal of the First Year in Higher Education 4(2): 131-136. doi: 10.5204/intjfyhe.v4i2.178

Taylor, Brian. 2015. “Developer's Dilemma by Casey O'Donnell Review: An Ethnography of Game Developers." Pastemagazine. com. Accessed October 8, 2018. https://www.pastemagazine. com/articles/2015/01/developers-dilemma-by-casey-odonnellreview-an-eth.html

Toor, Rachael. 2012. "Why Bother Writing Book Reviews?" Chronicle of Higher Education. Accessed March 1, 2018. https:// www.chronicle.com/article/Why-Bother-Writing-Book/131360

Torres, Lynette, and Sarah Jansen. 2016. "Working from the Same Page: Collaboratively Developing Students' Research Skills across the University." CUR Quarterly 37(1): 26-33. doi: $10.18833 /$ curq/37/1/9

Ventura, Elbert. 2012. "The Tea Party Paradox.” Columbia Journalism Review. Accessed October 8, 2018. https://www.cjr.org/ review/the_tea_party_paradox.php

Weetman, Jacqui. 2005. "Osmosis: Does It Work for the Development of Information Literacy?" Journal of Academic Librarianship 31: 456-460. doi: 10.1016/j.acalib.2005.05.007

Wiggins, Bradley E., and G. Bret Bowers. 2015. "Memes as Genre: A Structurational Analysis of the Memescape." New Media \& Society 17: 1886-1906. doi: 10.1177/1461444814535194

Wijayasundara, Nayana. 2008. "Faculty-Library Collaboration: A Model for the University of Colombo." International Information \& Library Review 40: 188-198. doi: 10.1016/j. iilr.2008.06.04

Willison, John, and Femke Buisman-Pijlman. 2016. "PhD Prepared: Research Skill Development across Undergraduate Years." International Journal for Researcher Development 17: 63-83. doi: 10.1108/IJRD-07-2015-0018

Willison, John, and Kerry O'Regan. 2007. "Commonly Known, Commonly Not Known, Totally Unknown: A Framework for Students Becoming Researchers." Higher Education Research \& Development 26: 393-409. doi: $10.1080 / 07294360701658609$

Worsham, Lynn. 2012. "The Endangered Scholarly Book Review." Chronicle of Higher Education. Accessed March 1, 2018. https://www.chronicle.com/article/The-EndangeredScholarly-Book/131361

\section{Nicholas J. Rowland}

Penn State Altoona, njr12@psu.edu

Nicholas J. Rowland is associate professor of sociology and environmental studies at Penn State Altoona. He is the university's first faculty scholar for the Engaged Scholarship Academy and a faculty fellow for the Schreyer Institute for Teaching Excellence. His interest in the sociology of science and engaged scholarship, emphasizing 
undergraduate research, motivates his collaborative work with librarians on how students learn information literacy. He received his PhD from the Department of Sociology at Indiana University.

Jeffrey A. Knapp is the Larry \& Ellen Foster Librarian for Communications at Penn State University Park. His academic background includes international politics and history, and he has professional experience in marketing communications. He considers it his job to be interested in everything. His research involves the role of academic librarianship in an ever-changing information environment. He received his master of science in library science from Clarion University of Pennsylvania.

Hailley Fargo is the student engagement and outreach librarian for Penn State University Park. Her focus in librarianship includes engaged scholarship, digital and information literacy, community informatics, reference services, peer-to-peer communities in the academic library, student work in the library, and community engagement. She received her master of science in library and information science at the University of Illinois at Urbana-Champaign.

\section{Looking for a past SPUR or CUR Quarterly article?}

\section{Visit CUR's online article search: https://bit.ly/SPUR-CURQSearch}

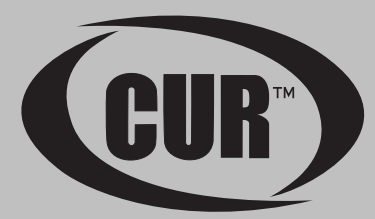

